\title{
Metodología para el análisis de las prácticas y políticas de ordenamiento territorial en América Latina. El caso de Argentina, Ecuador, México y Paraguay
}

\author{
Methodology for the analysis of land use practices \\ and policies in Latin America. The case of Argentina, \\ Ecuador, Mexico and Paraguay
}

\author{
Martha Villagómez* \\ Rosa Cuesta* \\ Marcelo Sili** \\ Antonio Vieyra***
}

Fecha de recibido: 09 de septiembre de 2019

Fecha de aceptado: 30 de marzo de 2020

\section{Resumen}

El presente artículo es producto de un proyecto de investigación cuyo objetivo principal fue presentar, sobre la base de experiencias de casos multiescalares (nacional, regional, rural y metropolitano), una metodología que permita conocer el estado de situación de las iniciativas de ordenamiento territorial en cuatro países de América Latina, señalando los principales factores que limitan o inhiben su puesta en marcha y sus resultados, de manera tal que se puedan plantear algunas pistas y recomendaciones para la mejora de las políticas y las prácticas de ordenamiento territorial en toda la región.

Instituto Geográfico Militar, Quito, Ecuador, correos electrónicos:

martha.villagomez@geograficomilitar.gob.ec; rosa.cuesta@geograficomilitar.gob.ec

* Acción y Desarrollo Territorial (ADETER), Universidad Nacional del Sur, Bahía Blanca, Buenos Aires, Argentina, correo electrónico: sili.marcelo@gmail.com

*** Centro de Investigaciones en Geografía Ambiental (CIGA), Universidad Nacional Autónoma de México (UNAM), Morelia, México, correo electrónico: avieyra@ciga.unam.mx 
El estudio fue ejecutado entre el 2017 y 2018, dentro Programa de Asistencia Técnica (PAT) que auspicia el Instituto Panamericano de Geografía e Historia (IPGH) dependiente de la Organización de los Estados Americanos (OEA), con la participación del Instituto Geográfico Militar del Ecuador, la Universidad Nacional Autónoma de México a través del Centro de Investigaciones en Geografía Ambiental (CIGA) del Campus de Morelia; el Centro de Investigación para el Desarrollo de Paraguay y la Universidad Nacional del Sur a través del Centro ADETER (Acción y Desarrollo Territorial) de la Argentina. A ello se sumó el apoyo de numerosos investigadores de otras Universidades y centros de investigación de los países involucrados.

En este marco de investigación, se planteó una estrategia que incluyó el trabajo de campo mediante entrevistas a actores importantes y conocedores de la problemática. Adicionalmente, se recopiló información secundaria de las fuentes oficiales de cada nación y en función de todos estos instrumentos se realizaron varios talleres y discusiones evidenciados en los productos entregados.

El resultado de la investigación reconoció problemas comunes en torno a la planificación territorial presentes en los cuatro países analizados, y que se manifiestan también en todos los niveles escalares; posteriormente, a partir de estos temas comunes para todos, con base en los instrumentos metodológicos desarrollados y el criterio experto de los participantes, se generaron propuestas que aportan ideas prácticas para mejorar las políticas de planificación territorial en América Latina.

Palabras clave: ordenamiento territorial, América Latina.

\section{Abstract}

This article is the product of a research project whose main objective was to present, on the basis of experiences of multiscale cases (national, regional, rural and city), a methodology that allows us to know the status of territorial planning initiatives in four Latin American countries, pointing out the main factors that limit or inhibit its implementation and its results, so that some clues and recommendations can be raised for the improvement of land use policies and practices throughout the region.

The study was executed between 2017 and 2018, within the technical assistance projects (PAT) sponsored by the Pan American Institute of Geography and History (PAIGH) that is dependent on the Organization of American States (OAS) and had the participation of the Military Geographic Institute of Ecuador, the National Autonomous University of Mexico through the Environmental Geography Research Center (CIGA) of the Morelia Campus, the Development Research Center of Paraguay and the National University of the South through the ADETER Center (Territorial Action and Development) of Argentina. To this was added the support of numerous researchers from other universities and research centers in the countries involved. In this research framework, the strategy included field work 
through interviews with important actors and knowledgeable about the problem. In addition, secondary information was collected from the official sources of each nation, based on all these instruments several workshops and discussions were held that allowed to obtain several products.

The result of the investigation recognized common problems around the territorial planning present in the four countries analyzed, and which are also manifested at all scalar levels; Subsequently, based on these common themes for all, based on the methodological instruments developed and the expert criteria of the participants, proposals were generated that provide practical ideas in order to improve territorial planning policies in Latin America.

Key words: territorial planning, Latin America.

\section{Introducción}

América Latina en las últimas décadas ha estado viviendo un profundo proceso de transformación territorial, producto de un modelo territorial estructurado por grandes ciudades y áreas rurales donde cohabitaban grandes latifundios con la agricultura familiar (FAO, 2014). Actualmente, se está cambiando a otro modelo de organización territorial más complejo, caracterizado por: a) el creciente peso de las ciudades (incluyendo ciudades medianas), con procesos de urbanización descontrolados, b) la emergencia de nuevas actividades productivas más diversificadas pero siempre sobre la base de la explotación de los recursos naturales, muchas veces no regulados o con alto impacto ambiental, c) las dinámicas demográficas más complejas en donde la migración sigue siendo moneda corriente, y d) una profundización de los desequilibrios territoriales, con regiones sumergidas en la pobreza, la marginación por un lado y otras zonas o bolsones de riqueza y prosperidad por otro, con zonas altamente congestionadas $\mathrm{y}$ fuertes problemas de transporte e infraestructura, $\mathrm{y}$ aquellas que se encuentran completamente deshabitadas o con densidades muy bajas, lo cual también configura una problemática para mantener la calidad de vida (Castro, 2014).

Es claro que América Latina, es actualmente y más que nunca un continente ávido de políticas y prácticas de ordenamiento territorial, necesarias para resolver estos problemas estructurales de sus territorios y conducir a los mismos hacia escenarios de una mayor calidad de vida, entendiendo a la planificación y ordenamiento como un proceso permanente y en constante mejora, que se conecta con los diferentes niveles de organización y jerarquía según la articulación de cada país.

Esta necesidad de mejora de las condiciones de los territorios es parte de la agenda de los países de la región. En efecto, detrás de este escenario de transformación (y degradación) territorial es posible observar en todo el continente la emergencia de planes, programas y proyectos de todo tipo 
(desarrollo local, desarrollo territorial, ordenamiento territorial, etc.) con el objetivo de mejorar las condiciones de vida, de producción o bien para ordenar los territorios revirtiendo los problemas de degradación o para que su funcionamiento sea más eficaz y conducente a escenarios de desarrollo. Esta multiplicidad de iniciativas se construye desde los gobiernos nacionales, provinciales o municipales, y también desde diferentes organizaciones sociales y empresariales, configurándose un ambiente político institucional sumamente complejo (Quenan, 2014).

No obstante, un elemento distintivo de este ciclo histórico signado por la "sobreabundancia" de iniciativas y proyectos de desarrollo y ordenamiento territorial, es que las mismas aparecen confusas, sin coordinación, muchas veces contradictorias o con superposición de objetivos y propuestas, y con objetivos muy poco claros o inalcanzables, ya sea por falta de instrumentos, por la incapacidad del Estado o por inadecuados modelos de gobernanza territorial. Todo ello conduce indefectiblemente a una muy baja eficacia de las iniciativas de ordenamiento territorial lo cual deja como contratara un desorden territorial caracterizado por congestión y descontrol de las ciudades, desequilibrios regionales muy marcados, degradación de ambientes y paisajes y por ende una pérdida de calidad de vida y competitividad territorial (Kleinpening, 1987).

Esta problemática no es específica de un país en particular, sino una problemática estructural de todos los países de América Latina. Desde el norte al sur del continente los proyectos con intencionalidades de ordenar los territorios se suceden, pero los problemas de orden territorial se suceden a velocidades mayores, pareciera que la solución de los problemas de congestión, desequilibrios, degradación ambiental, usos inapropiados del suelo, etc., son cada vez más lejanos. Este tema se lo puede visualizar a nivel nacional y en los niveles estatales, regionales, provinciales y municipales, aunque con especificidades y características propias de cada nivel escalar (Sili, 2011, 2017).

Con estos antecedentes, emergen varios cuestionamientos claves: ¿qué tipo de iniciativas de ordenamiento territorial emergen en América Latina? ¿qué tipos de problemáticas pretenden resolver estas iniciativas? ¿qué factores inhiben o limitan la eficacia de estas políticas y prácticas de ordenamiento territorial en la región? ¿qué se ha aprendido de esta experiencia? y finalmente, ¿qué recomendaciones se pueden plantear para mejorar la eficacia de estas iniciativas?

Estas interrogantes, que constituyen la base de una reflexión sobre las iniciativas y políticas de ordenamiento territorial en América Latina, ha motivado la puesta en marcha de un proyecto patrocinado por el Instituto Panamericano de Geografía e Historia (IPGH), dependiente de la Organización de los Estados Americanos (OEA), y cuyos actores son: la Universidad Nacional Autónoma de México a través del Centro de Investigaciones en Geografía Ambiental (CIGA) del Campus de Morelia, el Instituto Geográfico Militar del Ecuador, el Centro de Investigación para el Desarrollo de Paraguay y la Universidad Nacional del Sur a 
través del Centro ADETER (Acción y Desarrollo Territorial) de la Argentina. Estas Instituciones llevaron adelante un exhaustivo trabajo de campo y de análisis de información secundaria en México, Ecuador, Paraguay y Argentina, en diferentes provincias, ciudades y zonas rurales con el objetivo de poder dar respuesta a los grandes interrogantes planteados.

Los resultados de esta investigación colectiva, han permitido plantear algunas pistas y recomendaciones para la mejora de las políticas y las prácticas de ordenamiento territorial en la región, aunque es claro que los casos analizados no pueden completar el panorama total de las problemáticas territoriales de América Latina, por lo que no se pretende una exhaustividad territorial sino identificar las grandes problemáticas territoriales y las grandes líneas de políticas e iniciativas de ordenamiento territorial puestas en marcha en la región, los casos de análisis garantizan una diversidad geográfica, político institucional y de desarrollo económico productivo que permiten completar un cuadro de situación coherente con la situación estructural de América Latina (Comisión Económica para América Latina y El Caribe -CEPAL, 2014).

\section{Estrategia metodológica}

Desde la perspectiva de este trabajo, se entiende al ordenamiento territorial como una práctica llevada a cabo por los gobiernos para organizar y adecuar sus territorios en función de los objetivos de desarrollo planteados por la sociedad. Esto supone que detrás de toda práctica de ordenamiento territorial existe una intencionalidad política, un modelo de futuro al cual se quiere llegar y que por lo general se traduce en un Plan de desarrollo del territorio.

Así, un proyecto de desarrollo territorial señala las orientaciones de futuro de la sociedad definiendo estrategias y programas de diferente tenor (sociales, económicos, etc.) y la estrategia o el plan de ordenamiento territorial organiza el territorio para que el mismo viabilice y potencie dicha estrategia de desarrollo.

Con la finalidad de analizar estas prácticas y políticas de ordenamiento territorial en América Latina, se planteó el siguiente procedimiento, el mismo que tiene como objetivo convertirse en un estándar para comparar los procesos de ordenamiento que se dan en cualquier país latinoamericano.

a) Análisis de las condiciones territoriales en América Latina y la necesidad de políticas de ordenamiento territorial

b) Descripción y caracterización general del territorio analizado (Figura 1):

- Localización, organización espacial y territorial

- Historia espacial

- Población

- Dinámica económica

- Principales problemáticas y dinámicas territoriales emergentes 
En la Figura 1, se presentan las temáticas que fueron tratadas durante el análisis de la información de cada uno de los cuatro niveles escalares definidos, esta información está más detallada en el libro Ordenando territorios: experiencias y lecciones aprendidas de los procesos de ordenamiento territorial, producto del proyecto de investigación.
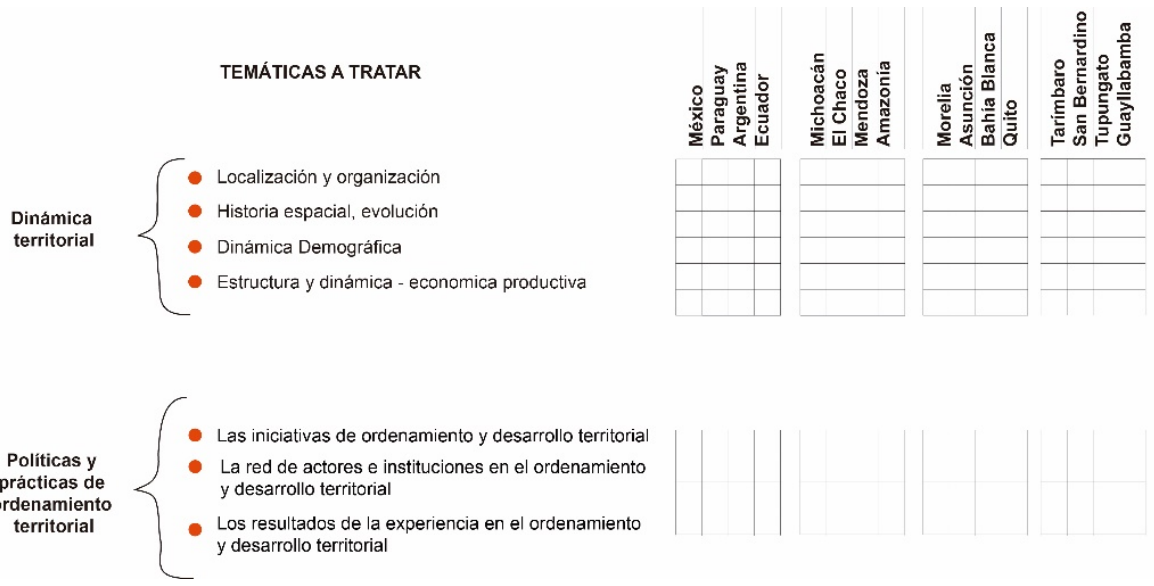

Figura 1. Instrumentos gráficos y herramientas para la modelización territorial de los procesos de OT.

c) Recopilación y análisis de información secundaria:

- Políticas, marcos legales, institucionales e instrumentos para el OT según nivel escalar analizado

d) Planificación de entrevistas a referentes claves, principalmente Directores y ex Directores de planificación y ordenamiento territorial, en base a una entrevista previamente desarrollada y consensuada con los actores del proyecto (Anexo 1).

e) Generación de la matriz de síntesis para el análisis y caracterización general del proceso de planificación considerando los siguientes temas generales (Figuras 2 y 3 ).

- Objetivos (verde claro)

- Componentes y actividades del plan (rojo)

- Actores involucrados y liderazgos (públicos, privados, colectivos) (celeste)

- Organización (azul)

- Mecanismos de participación (naranja)

- Presupuesto (verde musgo)

- Recursos técnicos (morado claro)

- Normativas (de sostén y de aplicación) (rosado)

- Nivel de implementación del plan (naranja pálido) 
- Factores que inhiben la iniciativa (verde)

- Factores que viabilizan la iniciativa (celeste pálido)

Las Figuras 2 y 3 sintetizan el análisis de cada uno de los temas antes descritos, evaluados en cada uno de los niveles escalares definidos (nacional, regional, metropolitano y rural), las celdas marcadas evidencian las variables que corresponden a cada nivel.

Dicha metodología fue puesta a prueba en el trabajo de campo realizado en cada uno de los países participantes del proyecto, implementando sistemáticamente cada paso en los países participantes, de esta manera se obtuvo productos que permitieron entender dos temas: los procesos de

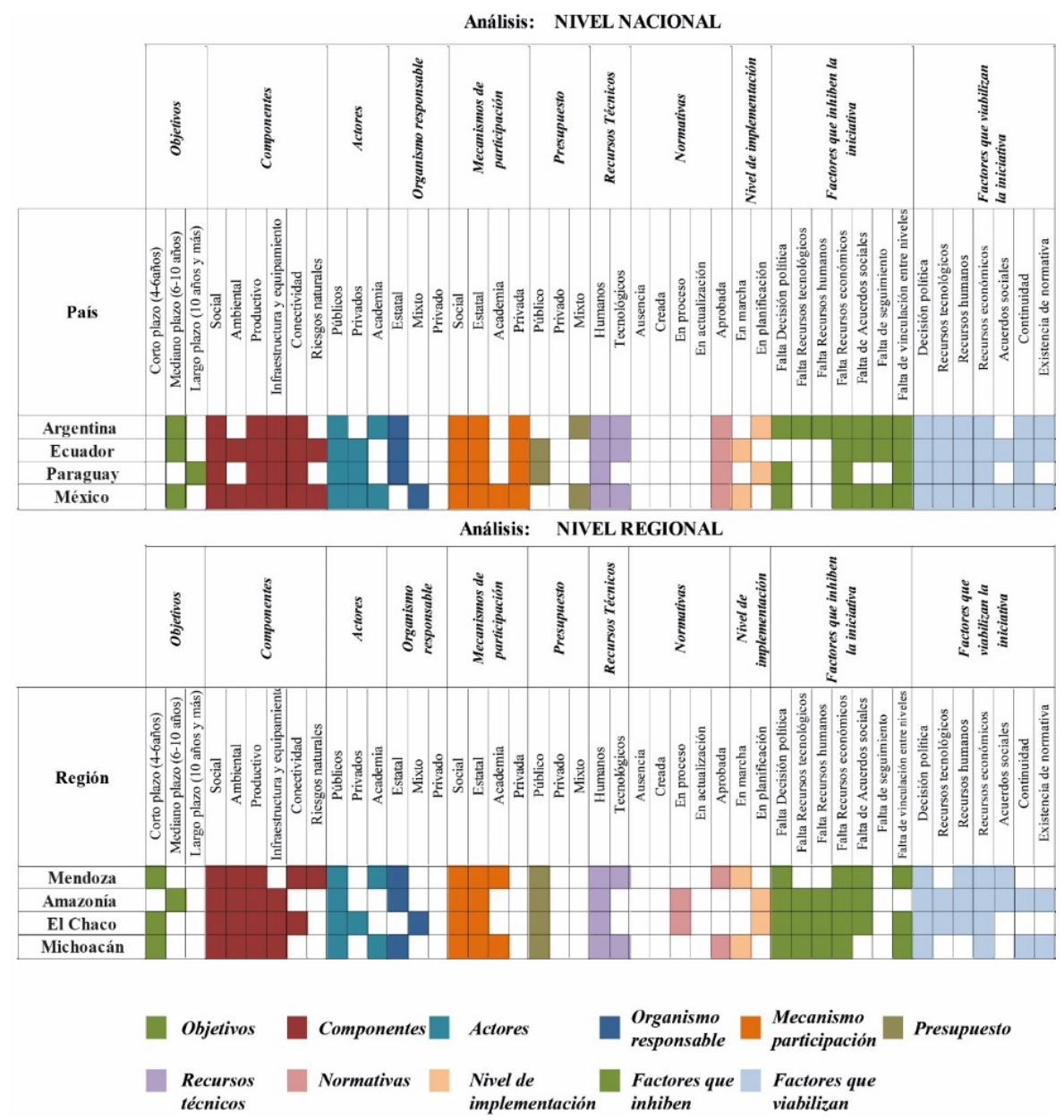

Figura 2. Matriz de comparación nivel nacional y regional. 
Análisis: NIVEL METROPOLITANO

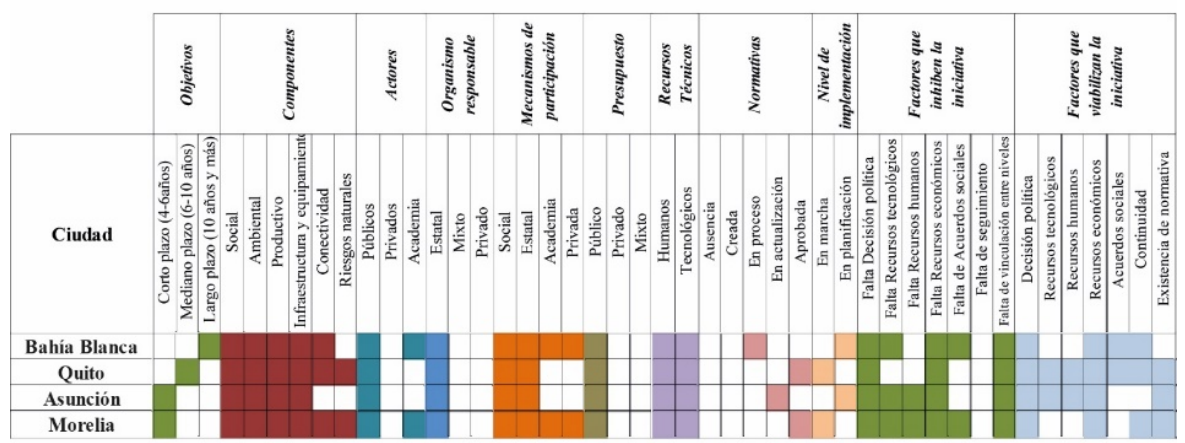

Análisis: NIVEL RURAL

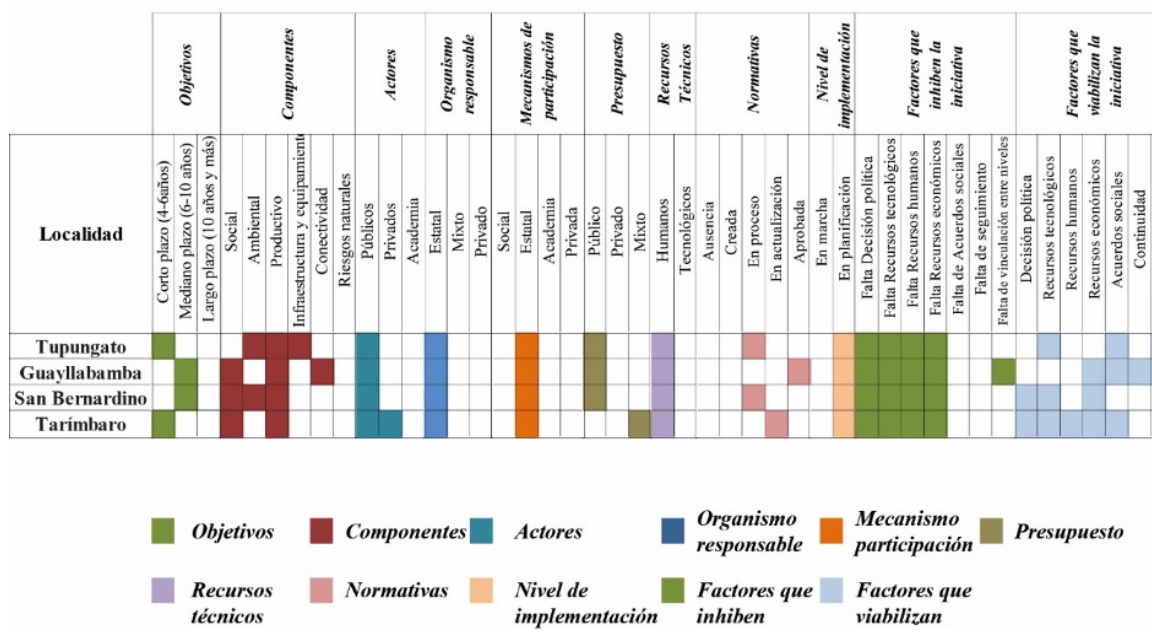

Figura 3. Matriz de comparación nivel metropolitano y rural.

transformación y las dinámicas territoriales en América Latina, instrumentos que a su vez, son los insumos básicos del análisis geográfico para comprender las prácticas y políticas de ordenamiento territorial, productos que se obtuvieron de cuatro niveles escales de análisis (nacional, regional, local o urbano y rural).

\section{Procesos de transformación territorial en América Latina}

\section{Sobre concentración urbana, crecimiento desordenado y desarrollo desequilibrado}

Una de las principales preocupaciones al momento de hacer ciudad, ya sea teórica o pragmáticamente, es que es un lugar habitado y, por tanto, debe ser habitable. No obstante, la experiencia histórica es que las ciudades no surgen 
para la mejor calidad de vida de sus habitantes, sino como el resultado de las fuerzas de producción. Simplemente no hay ciudad que no lleve a cabo procesos productivos y cuente con población empleada para ello.

Así, en términos de economía urbana, una ciudad es la expresión de la configuración territorial de los medios de producción, de las ventajas comparativas, de los ciclos de vida de esas ventajas y de la transacción de mercancías y servicios. De ahí que suceda una localización específica de las inversiones del capital y de las economías especializadas; en consecuencia, la estructura de una ciudad se torna heterogénea en cuanto a volúmenes de inversión, niveles de especialización económica o productiva, redes empresariales, densidades de población y condiciones de vida (Guibert et. al., 2011).

Partiendo de esta base, se entiende que las ciudades latinoamericanas enfrentan problemas estructurales como el crecimiento sobre concentrado o macrocefálico, el crecimiento desordenado, la especialización productiva y el consecuente desarrollo territorialmente desequilibrado.

Hay que tener en cuenta que el desorden con el que crece la ciudad no impide su funcionalidad productiva. Históricamente la configuración territorial de los medios productivos lleva un orden que ha permitido la producción y la regeneración de la inversión. Mientras que la especialización productiva (o bien, la falta de diversificación económica) se debe a que las ciudades se desarrollan en medio de un sistema económico basado en la propiedad privada (cuyos beneficios en buena medida también son privados) y en aprovechar las ventajas comparativas de cada una de ellas.

Parte de los problemas de las ciudades latinoamericanas también radican en el desequilibrio que se da en las inversiones, en las relaciones de poder, o en la asignación de recursos para servicios universales como la educación, la salud o la seguridad pública, por mencionar algunos; lo que finalmente impide alcanzar una ciudad incluyente. Si bien actualmente hay un amplio consenso para respetar la propiedad privada, esto ha llevado a que las ciudades (mediante sus gobiernos locales) pierdan potestad de los medios de producción, en consecuencia, restringen sus opciones para incrementar sus ingresos. En la medida en que una ciudad solo funciona como un conductor de capitales, éstos por consiguiente le son ajenos a su patrimonio público con los que atendería las necesidades públicas. Por el contrario, a fin de ofrecerse como ciudades competitivas, otorgan incentivos a la iniciativa privada para atraer inversiones. La idea es que sus ingresos se garantizan por la vía de los impuestos que tributan tanto las empresas como la ciudadanía beneficiada por esas empresas.

En realidad, lo que deja ver la experiencia es que la ciudad y todo el sistema de ciudades viene a dar estructura territorial a la generación y transferencia de las inversiones privadas; en los hechos, los costos de producción se socializan, puesto que para una empresa es desmedido hacerse cargo de la contaminación 
que provocan, de los problemas de movilidad, o de la atención de salud, educación o vivienda que requiere población residente.

\section{El lento proceso de planeación urbana en América Latina}

En este marco de desequilibrios, se generan múltiples necesidades y tensiones que son atendidas por el Estado mediante el ejercicio de la administración pública, particularmente la planeación territorial: transfiere recursos económicos a las ciudades, fomenta el desarrollo urbano, encausa o restringe su expansión física, programa las tasas de crecimiento poblacional, o bien abastece los servicios educativos, salud y de infraestructura. Es decir, le corresponde al Estado cuidar que las ciudades sean funcionales. No obstante, las tareas de planeación en América Latina se han tornado lentas (Esparza, 1995).

Hall dio cuenta de que la planeación urbana comenzó a practicarse desde finales del siglo XIX (Hall, 1996), pero en América Latina tardaría varias décadas más en instrumentarse, puesto que: 1) todavía a mediados del siglo $\mathrm{xx}$ era predominantemente rural; 2) varios países de la región han padecido un largo periodo de conflictos armados internos, con algunos casos en los que todavía no se resuelven $u$ otros en los que se detonan nuevos problemas bélicos; 3) en este sentido, en muchos de los países latinoamericanos los esfuerzos han sido enfocados por mucho tiempo en conformar los Estados-nación, en que se reconozca la legitimidad de una autoridad y en lograr la unidad nacional.

Así, las condiciones internas en América Latina para ejercer la planeación urbana con mayor consistencia, estuvieron dadas a partir de la segunda mitad del siglo $x x$, especialmente con el apoyo de un lenguaje matemático, con un razonamiento positivista (Gómez et al., 1994: 96-98) y con un conjunto de tecnologías como la informática, la estadística y la teledetección (Bosque y Ortega, 1995: 16-17), por lo que predominaba la intención de modelar la realidad.

En los años ochenta se experimentaría un parteaguas no solo en la planeación urbana, sino en la planeación económica y territorial, cuando tuvo lugar el Consenso de Washington, un conjunto de políticas económicas impulsado por el Fondo Monetario Internacional y el Banco Mundial (2007), dirigido especialmente a los países periféricos dados los problemas económicos mostrados en esos años, situación que llevó a muchos países latinoamericanos a suspender el pago de su deuda externa. En adelante, se volverían recurrentes las agendas internacionales - universalistas para instrumentar las políticas macroeconómicas, la privatización de las empresas estatales, el combate a la pobreza o la reducción de los desequilibrios territoriales. En 1992 fue celebrada en Brasil la Cumbre de la Tierra, una conferencia de Naciones Unidas, a raíz de la cual se generó la denominada Agenda 21 como un plan de acciones que habría de adoptarse de manera universal, nacional y local para encausarse en el desarrollo sostenible con base en ejes como la conservación y gestión de los recursos, o el fortalecimiento institucional de los gobiernos nacionales y locales. 
Hacia finales de los años noventa cobró relevancia la conceptualización de otro instrumento de planeación, el ordenamiento territorial, entre cuyas novedades figuraron un enfoque prospectivo de largo plazo, el seguimiento y evaluación periódica del ordenamiento, el manejo sustentable de los recursos naturales, y la participación de los diversos actores sociales relacionados con el territorio. Mientras que, de manera reciente, en 2015, Naciones Unidas impulsó la Cumbre del Desarrollo Sostenible, con base en la cual en 2016 entró en vigor la Agenda 2030 para el Desarrollo Sostenible (Naciones Unidas, 2018). Este Acuerdo contiene 17 Objetivos de Desarrollo Sostenible (ODS) también de aplicación universal, entre los que figuran: 1) Ciudades y comunidades sostenibles, 2) Acción por el clima, 3) Fin de la pobreza, por mencionar algunos. Como se puede observar, a diferencia de otros tiempos, en los últimos años se tiene la intención de planificar el territorio integrando diagnósticos y acciones con todos los ejes temáticos posibles, no solo los económicos o de estructura urbana.

\section{El ordenamiento urbano en América Latina según la Agenda 2030}

No obstante, de esta trayectoria en la planeación urbana y territorial, desde el Consenso de Washington han pasado cerca de 40 años sin que se haya logrado un satisfactorio desarrollo de las ciudades latinoamericanas y un equilibrado ordenamiento territorial. Tal parece que el problema es que, según advierte Iracheta, los planes de desarrollo tienen lugar sin que necesariamente coexista la suficiente intencionalidad política que garantice su cumplimiento (Iracheta, 2002: 71). Pero también hay que tomar en cuenta que el orden internacional antepone a cualquier nación latinoamericana el control de los principales indicadores macroeconómicos (pago de deuda internacional, tasas de inflación, tasas de interés, niveles de inversión...). La resistencia a esto, pone en tela de juicio la buena integración de un país a la economía global, vigilados por instituciones internacionales como el Fondo Monetario Internacional, el Banco Mundial o las diversas calificadoras internacionales (como Estandard and Poor's, Moody's o Fitch, entre otras) (Szary, 2003).

Aunque se esté de acuerdo o no con este orden internacional, se ha vuelto de observancia obligada el diagnóstico y las opciones de desarrollo diseñadas en mecanismos globales como la Agenda 2030. De hecho, luego de aprobada esta Agenda, en mayo de 2016 tuvo lugar el Foro de los Países de América Latina y el Caribe sobre Desarrollo Sostenible, en el que se refrendó que los 17 Objetivos de Desarrollo Sostenible (ODS) de la Agenda 2030 representan en adelante los retos a enfrentar de manera global, nacional y local; es decir, los ODS se han convertido en la agenda pública para los países latinoamericanos y sus diferentes niveles territoriales de gobierno. Estos ODS son:

- Fin de la pobreza

- Hambre cero
- Educación de calidad

- Igualdad de género 
- Salud y bienestar

- Energía asequible y no contaminante

- Trabajo decente y crecimiento económico

- Industria innovación e infraestructura

- Reducción de las desigualdades

- Ciudades y comunidades sostenibles
- Agua limpia

- Producción y consumo responsable

- Acción por el clima

- Vida submarina

- Vida de ecosistemas terrestres

- Paz, justicia e instituciones sólidas

- Alianzas para lograr los objetivos

Cada uno de estos Objetivos de Desarrollo Sostenible cuenta con metas de entre las que enunciamos solo dos ejemplos. Con el primer ODS se aborda la pobreza más allá de la falta de ingresos para sostenerse, al extender la problemática a la falta de vivienda digna y el acceso limitado a servicios básicos que desembocan en una exclusión social. De dicha situación surge la necesidad de crear marcos normativos sólidos para establecer estrategias de desarrollo en favor de los pobres.

Con el décimo primer ODS (Ciudades y comunidades sostenibles) se exhibe que el mundo ha experimentado un crecimiento urbano sin precedente en los últimos decenios, lo que demanda mejorar la planificación para: 1) que los espacios urbanos sean más inclusivos, seguros, resilientes y sostenibles; 2) reducir significativamente el número de muertes causadas por los desastres, incluidos los relacionados con el agua, haciendo especial hincapié en la protección de las personas en situaciones de vulnerabilidad; 3) reducir el impacto ambiental negativo de las ciudades, prestando especial atención a la calidad del aire y la gestión de los desechos municipales y de otro tipo; 4) apoyar los vínculos económicos, sociales y ambientales positivos entre las zonas urbanas, periurbanas y rurales.

Sea de donde provenga la naturaleza de la Agenda 21, la Agenda 2030 o cualquier otra estrategia que impulse el ordenamiento urbano y territorial, lo importante siempre será comprometerse con los objetivos planteados, tanto desde los ámbitos gubernamentales como sociales, nacionales y locales, de otra manera seguirá corriendo el tiempo sin que se resuelvan los grandes retos que afrontamos.

\section{La intensificación de las presiones económicas y sociales sobre los recursos naturales}

La región conformada por América Latina y el Caribe (ALC) es amplia y diversa políticamente, geográficamente, económicamente y ecológicamente y si bien, actualmente conserva gran parte de su biodiversidad se ha producido una pérdida considerable (Aguilar et al., 2016). 
Esta situación responde a diversas fuentes de presión sobre los recursos naturales ya sea para hacer un uso directo de los mismos (madera, carne, pieles, etc.) o para hacer uso del espacio que estos ocupan (e.g. cambio de cubierta forestal por monocultivos). Entre estas presiones se puede mencionar el rápido crecimiento económico y la desigualdad social (UNEP-WCMC, 2016). Se han encontrado correlaciones entre la pobreza y el deterioro de la biodiversidad en las regiones tropicales (WWF 2014); en la región de ALC más del 25 por ciento de la población urbana vive en condiciones de pobreza extrema, y el 20 por ciento más rico gana 20 veces más que el 20 por ciento más empobrecido (onU-Hábitat 2012).

En la región continúa la intensificación agropecuaria transformando en consecuencia grandes extensiones de bosques hacia cubiertas más acordes con estas actividades (pastizales) y favoreciendo la fragmentación e incluso el sobrepastoreo de los pastizales convertidos (Michelson, 2008). Según el último informe de la Organización de las Naciones Unidas para la Alimentación y la Agricultura (FAO, 2016) sobre el estado de los bosques, la agricultura comercial origina casi el $70 \%$ de la deforestación en América Latina. Adicionalmente las prácticas productivas que tienen lugar en los espacios transformados pueden acarrear otras presiones como por ejemplo el uso de organismos genéticamente modificados (OGM) en la agricultura que impacta sobre la agrodiversidad existente. No se debe olvidar que en ALC se encuentran seis de los 17 países megadiversos del mundo, en los que hay un gran número de endemismos. Así mismo la región es reservorio de varios centros de domesticación que han contribuido a la agrobiodiversidad y la seguridad alimentaria del planeta.

Los fuertes crecimientos económico y demográfico impulsan acciones destinadas a satisfacer las necesidades de la población y las actividades económicas que realiza, por lo que la región experimenta un fuerte desarrollo de infraestructura de diques y carreteras. Brasil, Chile y Ecuador son los países con la mayor densidad de nuevos proyectos de represas desarrollados en la última década (Kareiva, 2012). El desarrollo de infraestructura para el crecimiento de las ciudades, el comercio y el transporte de bienes y pasajeros, están impulsando la expansión de nuevas carreteras hacia zonas que previamente permanecían como áreas naturales silvestres.

Las economías de los países dentro de la región son muy dependientes de sus recursos naturales. Por ejemplo, la energía hidroeléctrica representa más de dos tercios del suministro de energía de Brasil, donde se espera la conclusión de los procesos de construcción de 334 presas planificadas (Zarfl et al., 2015). La extracción de recursos minerales e hidrocarburos ha llevado a la devastación local con impactos directos e indirectos sobre el ambiente y la salud humana (Bebbington y Bury, 2013).

La contaminación atmosférica es reconocida hoy en día como un factor ambiental que incide en la salud humana de la región. Varios estudios sugieren 
vínculos entre la presencia de material particulado y el aumento de la mortalidad prematura entre la población (Ochoa-Acuña y Roberts, 2003).

Tales impactos en la calidad de vida y en los indicadores del desarrollo humano de la población de América Latina son hoy día grandes retos, que implican repensar el modelo imperante del aprovechamiento de los recursos y la puesta en práctica de estrategias de ordenamiento territorial efectivas, que incidan en una mayor equidad social.

\section{Dinámicas territoriales de nivel nacional en América Latina}

En las últimas décadas América Latina ha vivido procesos de transformación territorial singulares. Una dinámica muy importante ha sido el fuerte proceso de urbanización y el fortalecimiento de las economías de aglomeración, especialmente en las grandes ciudades y áreas metropolitanas (San Pablo, México, Bogotá, Buenos Aires, Santiago de Chile, etc.). Esto ha incrementado la concentración económico-productiva, alejando toda posibilidad de un desarrollo equilibrado y balanceado entre las diferentes regiones.

Otra dinámica clave ha sido el fuerte desarrollo de los espacios de flujos de mercaderías, debido a las nuevas inversiones y a un mayor flujo de tránsito internacional. Un ejemplo de ello, es el desarrollo de las ciudades portuarias en todo el continente, las cuales juegan un rol cada vez más importante, no solo como acceso para la importación y exportación de productos, sino también como áreas industriales de envergadura, debido a la mayor vinculación comercial y a los bajos costos relativos de los fletes en dichas áreas.

Otro cambio significativo de este nuevo período, ha sido el fortalecimiento de los procesos selectivos de desarrollo local, basados en pequeñas y medianas empresas, vinculadas a actividades turísticas y agroindustriales dinámicas, bajo modelos organizacionales innovadores, permitiendo consolidar centros urbanos intermedios y menores y las redes urbanas que integran. En este caso, es interesante observar, a manera de ejemplo, cómo muchas localidades han manifestado un desarrollo continúo debido a la combinación de varios elementos (universidades, escenarios naturales, sistemas productivos competitivos, etc.), los cuales, articulados y puestos en sinergia, han generado un desarrollo superior al de las ciudades más cercanas. Por otro lado, vastas áreas rurales de América Latina se han consolidado como desiertos verdes, o desiertos de producción agropecuaria, dedicados a la exportación.

Estas áreas, volcadas a una producción internacionalmente competitiva, están desarrolladas bajo modelos productivos modernos, con alta incorporación de tecnología y una reducida demanda de mano de obra altamente calificada. Este sistema, que ocupa muchas más hectáreas que en el pasado, expulsa la población rural hacia las ciudades de orden regional, pues todos los procesos productivos son operados desde las mismas explotaciones o desde las ciudades cercanas, pero con un mínimo de población. Como contraparte, las regiones y 
ciudades fuertemente asociadas al modelo productivo tradicional y de bajos niveles tecnológicos vinculado a la agricultura, la ganadería, la forestación y las actividades conexas en las áreas rurales, están siendo marginadas debido a que no alcanzan los niveles de competitividad necesarios para insertarse en forma sostenida dentro de un mercado global.

De esta manera se observa en toda América Latina como el proceso de globalización tiene impactos diferenciales en los territorios, mientras algunas áreas crecen y se desarrollan (las regiones que ganan), otras se empobrecen. Esta dialéctica territorial entre regiones ganadoras y regiones perdedoras ha marcado la dinámica territorial en los últimos años, fragmentando y desequilibrando aún más las históricas diferencias territoriales en el continente. Así, la globalización, actuando a través de procesos de desarrollo económico y productivo valoriza ciertos espacios competitivos, dinámicos y bien integrados, en tanto margina a espacios de baja competitividad o nivel de modernización e integración. Esta capacidad de valorización e integración es selectiva: solamente los lugares que han alcanzado ciertos niveles previos de desarrollo (infraestructura, calificación laboral, nivel tecnológico, servicios, etc.) pueden acceder a las nuevas oportunidades que ofrece el proceso de globalización (Safarov, 2000). En otras palabras, la globalización ha representado una oportunidad para los territorios con niveles medios de desarrollo y dotados de capacidades estratégicas relevantes o de recursos naturales a bajo costo (suelo, agua, bosques). Se ha ido construyendo así una nueva división del trabajo internacional y una nueva geografía económica, en la cual coexisten regiones que ganan y regiones que pierden (Gaignard, 1973).

Frente a los históricos desequilibrios territoriales, y en muchos casos de economías fragmentadas y en declinación, muchos gobiernos de América Latina han realizado esfuerzos para reconstruir propuestas de desarrollo nacional, con fuerte asidero en la dimensión territorial. Así, muchos países han puesto en marcha planes de ordenamiento territorial o estrategias territoriales de diferente tenor y alcance, con el objetivo de equilibrar e integrar sus territorios, y generar las condiciones para asegurar la sustentabilidad de sus sistemas productivos, especialmente de origen agropecuario. En este nuevo contexto el territorio aparece como el ámbito desde donde se articula, coordina y consensuan las iniciativas sectoriales. Un elemento saliente y de sumo interés es que las nuevas iniciativas de planificación territorial se apoyan en una fuerte visión prospectiva, con un claro mensaje político sobre el futuro deseado.

No obstante, el nivel de implementación de las estrategias y planes de ordenamiento territorial de nivel nacional son muy disímiles entre países. Todas cuentan con documentos bien elaborados y con buenas propuestas técnicas, pero no siempre están acompañados de los marcos normativos, de los modelos de gobernanza, ni de los instrumentos técnicos para su correcta implementación.

Para poder evaluar estas iniciativas se presentan a continuación cuatro grandes experiencias en América Latina, en primer lugar el caso de México, país 
federal con una fuerte diversidad y complejidad territorial, en segundo lugar el caso de Ecuador, con una fuerte biodiversidad y complejidad territorial producto de sus condiciones naturales, en tercer lugar el caso de Paraguay, país de carácter unitario, con un gobierno central fuerte y por lo tanto con requerimientos de gobernanza territorial diferentes al resto de los países analizados. En cuarto lugar, se presenta el caso de la Argentina, país que construyó en las últimas décadas una política nacional de ordenamiento territorial, situación inédita en este vasto país (Moreno, 1979).

\section{Hallazgos y resultados}

\section{Procesos de ordenamiento territorial por país}

A nivel nacional se puede destacar que, México, aunque hoy en día se consolida la base teórico-conceptual de los programas de ordenamiento y se mejoran los principios metodológicos para su elaboración con una notable participación del sector académico y de la población y además se reconocen los enfoques holísticos en las metodologías propuestas, aún queda mucho por avanzar, el proceso de planeación territorial tiene aún importantes retos (Méndez y Vieyra, 2014).

La problemática relacionada con el Ordenamiento Territorial, a nivel nacional, en México, es muy variada dada la complejidad originada por diferentes instrumentos de planeación en los territorios (OT, OET, PDU) de forma paralela, sin embargo, esta situación no es la única limitante al desarrollo del Ordenamiento en el país (Estados Unidos Mexicanos, 1930).

La existencia de varios instrumentos en la planificación física significa gastos al presupuesto por estudios similares, dificulta su implementación en particular cuando surgen contradicciones en los territorios sobre las políticas públicas aplicadas y las que se proponen en estos instrumentos. El carácter sectorial de la planeación económica, su verticalidad y falta de transversalidad, complica la creación y ejecución de los programas relacionados con las formas de ordenamiento, en numerosas ocasiones los planes sectoriales de desarrollo sustituyen a los instrumentos desordenamiento, por lo que algunos estados no hacen el plan de ordenamiento territorial y el plan de desarrollo urbano, sustituyéndolos por los planes sectorial de desarrollo planteados por la administración correspondiente (Unikel et al., 1978).

Por otra parte, los programas estatales de ordenamiento elaborados, por ley, deben responder a los planes de desarrollo del estado, cada nuevo gobierno estatal establece, también por ley, un nuevo plan de desarrollo, que en muchas ocasiones se contradice con los programas de ordenamiento, o no coinciden temporalmente, ello debilita al ordenamiento que pasa a un segundo plano al no existir una política que le dé continuidad. Además, al ser indicativos los instrumentos de ordenamiento, no existe la obligación de su cumplimiento, ni 
existen sanciones para quien falte al mismo. Si a ello sumamos que no existe conocimiento del significado y trascendencia del ordenamiento territorial en las estructuras de gobierno de los estados, incluso al máximo nivel, y que se presenta una falta de transversalidad entre las secretarías de cada nivel de gobierno, la situación empeora para el ordenamiento territorial. En algunos estados, la falta de articulación vertical de sus ordenamientos con los de los municipios, pone en evidencia serias contradicciones en las políticas y estrategias a la hora de ordenar el territorio.

La mayoría de los conocimientos y aplicaciones alcanzados en la planeación territorial y en sus intentos de implementación derivan de la comunidad académica nacional, del trabajo de consultorías, de la divulgación periodística y de grupos sociales, sin embargo, una gran parte de los municipios, e incluso algunos estados, no cuentan con el personal técnico que pueda implementar los ordenamientos, tampoco cuentan con el soporte tecnológico que les permita el procesamiento automatizado de la información estadística y geográfica. En general, los estados y municipios no poseen información concentrada de los programas sociales, de protección de la naturaleza, de infraestructura, entre otros, que desarrollan los sectores de su administración y, en ocasiones, por intereses políticos o de otra índole, se oculta y no se transparenta la información. Ello limita el uso de los programas por los tomadores de decisiones.

Aunque los ordenamientos realizados en la actualidad, tienen una importante participación de la ciudadanía, existe un desconocimiento grande por parte de la población del uso e importancia de estos instrumentos, ello limita el apoyo en la implementación de los programas, falta una base social al ordenamiento, en particular a nivel municipal.

Para el caso de Ecuador, las normativas resultantes de la política estatal se desprenden del Plan Nacional de Desarrollo (2017-2021) "Toda una Vida" que parte de la premisa del "Buen Vivir", el mismo que fue aprobado en sesión del 22 de septiembre de 2017, mediante Resolución No. CNP-003-2017, son elementos constitutivos: el Plan de Estrategia Territorial, el Plan Geográfico Nacional, los Criterios para orientar la Asignación de Recursos Públicos y la Inversión Pública y el Plan Plurianual De Inversiones (López, 2015).

El plan fue concebido en base a la Agenda 2030 y a los Objetivos de Desarrollo Sostenible de la ONU lo que permite la prolongación del plan pensando como Estado, más allá de los años que dura el Gobierno con la ayuda de gran cantidad de información geográfica generada en los últimos años que permiten tener instrumentos técnicos para la planificación. Todo esto ha permitido también crear, mantener y difundir un formato único y consensuado para el manejo de la misma información base en cualquier instancia de gobierno (local, metropolitano, regional), un espacio de articulación de la planificación entre diversas instituciones y de la implementación en conjunto con los GAD's locales y regionales, y promover la gestión de la planificación desde el nivel ejecutivo más 
alto del Gobierno, es decir el propio Presidente de la República encabeza la planificación estatal.

Esta voluntad política para el desarrollo equilibrado del país, decisión y entendimiento de la política por parte de las autoridades incluye mayor comprometimiento con la nación y por tanto la facilidad de alianzas con la cooperación internacional, la academia y otros actores que conocen su territorio para mejorar la gestión.

Lo que queda por cumplir es la etapa de comprobación en el ciclo de calidad de la política pública, es decir tomar las experiencias y verificar que funcionó y que se debe mejorar, el reto es como las lecciones aprendidas regresan al diseño de la política pública y se modifica la planificación, con esta revisión se puede definir si el presupuesto respondió a la planificación y viceversa, puesto que la situación económica del país puede llegar a ser un limitante.

Finalmente, se puede añadir, en base a la experiencia de la Secretaría Nacional (actual Planifica Ecuador), que la planificación multinivel y vinculante amerita un sinnúmero de estrategias (modelos de gestión, etc.) lo que desgasta la gestión pública y se vuelve un poco burocrático los procesos de planificación en el país.

En cuanto a Paraguay, la trayectoria histórica de la planificación territorial en Paraguay ha sido muy pródiga en términos de generación de iniciativas, aunque ha tenido muy bajo impacto en términos de mejora de la organización y el desarrollo de los territorios. Esta trayectoria ha dejado grandes enseñanzas sobre el funcionamiento de la planificación y sobre sus debilidades, las cuales interesa sistematizar para poder generar políticas correctivas hacia el futuro. Entre las principales debilidades, se pueden observar las que a continuación se detallan.

La principal debilidad en el sistema de planificación y gestión territorial de Paraguay es la preeminencia de una visión muy limitada o reduccionista del rol de la planificación y el ordenamiento territorial en torno al desarrollo. Los gobiernos y los líderes políticos, acuciados por encontrar respuestas rápidas a las problemáticas estructurales del país, visualizan a la planificación como un proceso de muy largo plazo, y por lo tanto inútil para resolver los problemas de sus territorios, especialmente a nivel nacional y departamental. Esta falta de visión y de entendimiento sobre las necesidades de poner en marcha este tipo de políticas y acciones se traduce, o bien en la inexistencia de planes, programas y proyectos eficaces, o bien en su debilidad y bajo impacto.

Una segunda problemática tiene que ver con el predominio de enfoques verticales y jerárquicos. En los procesos de planificación del desarrollo territorial en Paraguay prevalece claramente un enfoque de arriba hacia abajo (top down). Cuando los gobiernos diseñan un plan, el mismo se realiza con la participación de una consultora o una universidad, sin la participación de la sociedad civil y con escaso diálogo con los otros niveles escalares. Este tipo de enfoque ha sido priorizado por el Gobierno central para poder contar en forma rápida con un plan que permita darle credibilidad al gobierno y una imagen de racionalidad y ordenamiento en su gestión. Sin embargo, en la mayor parte de los casos, tales 
planes quedan solo como buenos documentos técnicos que no llegan a pasar a la fase de implementación.

En tercer lugar, muchas de las iniciativas puestas en marcha responden a una mirada que sigue siendo sectorial, sin que se promuevan las vinculaciones con otros sectores. Apoyada en la lógica del desarrollismo y del Estado benefactor, dicha mirada parece no tener en cuenta que en la actualidad se debe operar bajo la lógica de redes interconectadas, que operan en forma dinámica y flexible. La mirada sectorial contribuye claramente a la falta de coordinación interinstitucional. Las instituciones responsables de la planificación y la gestión de los planes y programas de desarrollo y ordenamiento territorial tienen estructuras institucionales de carácter vertical, propias del modelo de Estado fordista. Este modelo de organización les impide generar espacios o plataformas de gestión y coordinación capaz de garantizar la gobernanza de los planes y programas. De ahí que un problema clave, claramente denunciado, sea la falta de diálogo, de coordinación y de complementariedad de las iniciativas en marcha. Esta situación se evidencia claramente por la superposición de acciones entre diferentes Ministerios, así la Secretaría Técnica de Planificación (2016), responsable de la política de planificación nacional, ha diseñado el Plan Nacional de Desarrollo, construyendo el Paraguay del 2030, además ha puesto en marcha los planes de desarrollo local junto con los municipios, sin embargo otros Ministerios han puesto en marcha otros planes sectoriales como Plan Nacional del Hábitat y la Vivienda, Plan Ambiental, Plan Vial Ñamopora Ñanderape, Programa de Desarrollo Rural Sostenible, etc., todos ellos actúan en forma independiente sin articulaciones permanentes con el Plan Nacional de Desarrollo, el cual se supone constituye el marco de referencia de la planificación y el desarrollo territorial en el país.

La falta de recursos humanos capacitados es una debilidad clave en el sistema de planificación en Paraguay. Si bien en las últimas décadas se manifestó una clara voluntad orientada a la creación de ámbitos institucionales para la planificación y el ordenamiento territorial, como ha sido el Sistema Nacional de Planificación (SISPLAN), todavía no se cuenta con la densidad necesaria de recursos humanos capacitados en materia de planificación y gestión del desarrollo y, especialmente, con capacidad para conformar equipos multidisciplinarios. El único ámbito estatal que cuenta con recursos para la planificación territorial en Paraguay es la Secretaría Técnica de Planificación (10 técnicos formados en temas de planificación) y en menor medida la Secretaría de Ambiente. Los sistemas académicos en el país tampoco cuentan con los espacios de formación necesarios para reconstruir estas capacidades en torno a nuevos enfoques y metodologías de intervención que permitan pasar de una gestión de proyectos sectoriales a proyectos territoriales más complejos y conflictivos.

Finalmente, se puede observar que los procesos de planificación en Paraguay no han generado o acumulado experiencias de las cuales aprender: todo proceso de planificación que emerge se enfrenta a los mismos desafíos que los anteriores; 
no ha existido una capacidad de aprendizaje institucional en torno a la planificación y el desarrollo territorial que permita capitalizar conocimientos sobre qué hacer y cómo llevar adelante procesos más efectivos de ordenamiento territorial. Un elemento que ha contribuido a la discontinuidad y a la anarquía de procesos es la presencia de numerosas agencias de cooperación que llevan adelante proyectos de ordenamiento territorial, cada una de estas agencias (cooperación alemana, cooperación japonesa, cooperación francesa, etc.) aportan sus metodologías, enfoques e instrumentos, pero no se coordinan con los planes o estrategias nacionales, por lo cual no permiten construir un aprendizaje compartido ni acumular conocimientos que sirvan para sostener y madurar nuevas prácticas. Una vez que el proyecto de cooperación técnica y su financiamiento finaliza, los equipos técnicos se desarman, sin que se pueda recuperar la experiencia y sus resultados.

En líneas generales, todas estas debilidades han transformado a la planificación en un ejercicio técnico que pocas veces es tomado en cuenta al momento de la toma de decisiones. Al no coordinarse las acciones, al no crearse redes ni sinergias necesarias para apalancar las políticas públicas, el ordenamiento territorial termina siendo un ejercicio muchas veces estéril, lo cual contribuye a robustecer una suerte de círculo vicioso, pues la falta de resultados promueve aún más la desconfianza en el sector público y en la planificación como herramienta del cambio.

En este nuevo contexto histórico, es claro que ya no alcanza con mantener un orden jerárquico y garantizar el cumplimiento de las órdenes de los gobiernos centrales, sino que es necesario buscar nuevos mecanismos que permitan resguardar la compatibilidad y la coherencia de los objetivos, políticas y acciones nacionales, subnacionales y locales que se planteen, teniendo en cuenta que ahora todos los niveles escalares tienen interés en construir procesos de desarrollo.

$Y$, finalmente en el caso de Argentina, se muestra la experiencia con cuatro grandes limitantes para el diseño y la gestión de procesos de ordenamiento territorial.

1. La fuerte fragmentación y desarticulación de iniciativas de planificación y gestión territorial, entre diferentes organismos y actores del mismo nivel político administrativo, como entre diferentes niveles políticoadministrativos (nación, provincias y municipios), (Subsecretaría de Planificación Territorial de la Inversión Pública, 2015). Esto se debe a varias razones: a) a que las iniciativas de carácter territorial están distribuidas en múltiples y diversos organismos, tanto a nivel nacional, provincial como municipal; por tal razón, varios organismos trabajan en paralelo sobre temas similares, compartiendo el mismo territorio de acción, pero operando en forma autónoma e independiente, b) a que existen pocos mecanismos de articulación al interior de los ministerios, secretarías o direcciones, no 
existiendo además un organismo de carácter nacional con capacidad de articular todas las iniciativas de carácter territorial de todos los Ministerios, c) a la superposición de roles y funciones entre los diferentes niveles escalares, pues no existe claridad sobre las incumbencias y los instrumentos de que dispone cada uno de los niveles político-administrativos para tratar las problemáticas del territorio y d) a que existe una fuerte competencia política entre actores, ya que los problemas del territorio son una arena de disputas, en la cual distintos actores políticos intentan posicionarse y construir su poder y sus proyectos de futuro. De manera tal, que la problemática territorial no es atendida como un tema clave de las políticas públicas, sino que es utilizado como un pretexto para construir poder y escalar posiciones en la esfera política (Ríos, 2011).

2. El bajo nivel de organización de los procesos participativos (Subsecretaría de Planificación Territorial de la Inversión Pública, 2015). La experiencia argentina muestra que, aunque existe una gran diversidad de mecanismos y formas de participación en torno a la planificación territorial, no están adecuadamente organizados ni suficientemente normados como para generar efectos significativos y una mayor sostenibilidad del proceso planificador.

3. El vacío normativo, es decir la falta de un andamiaje jurídico que los sustente y estructure a partir de un marco legal. Argentina carece de una Ley Nacional de Ordenamiento Territorial; por su parte, las provincias tampoco cuentan con leyes provinciales de ordenamiento territorial (a excepción de Mendoza). Esto no permite sostener ninguna propuesta operativa de planificación y gestión territorial a largo plazo. A nivel local, los marcos normativos o leyes normalmente se centran en regular el uso del suelo urbano $u$ otras acciones vinculadas al ordenamiento territorial, sin que existan experiencias significativas de ordenanzas de carácter integral para sostener procesos de planificación y gestión que involucren las áreas urbanas y rurales (en este sentido, los municipios mendocinos también son la excepción, pues cuentan con ordenanzas locales para sostener los proyectos de ordenamiento territorial local, tanto urbanos como rurales).

4. La baja capacidad técnico-operativa en materia de planificación y gestión territorial. En la Argentina la planificación territorial está orientada a la planificación urbana; dentro de este ámbito, los equipos técnicos están monopolizados por arquitectos, siendo muy limitada la participación de otros profesionales -ingenieros, geógrafos, antropólogos, economistas, sociólogos, biólogos, etc.- en los equipos de planificación, con la consiguiente pérdida de diversidad de miradas y de capacidades técnicas. Estas carencias están condicionadas por tres hechos clave: el sesgo urbano de la planificación, la falta de una visión más sistémica de los procesos territoriales y, más ampliamente, la poca importancia histórica que se le ha dado al ordenamiento territorial en Argentina (Ríos, 2011). Asociado a esta 
baja capacidad operativa hay que mencionar también la carencia de instrumentos operativos, esto es, la falta de información (bases de datos, catastros), el bajo nivel de desarrollo de los instrumentos de tratamiento y visualización de la información territorial (GIS, WEB, etc.) y la casi nula utilización de modelos y métodos de planificación ya probados a nivel internacional (modelos de análisis y simulación territorial, modelos de planificación del uso del suelo, metodologías de seguimiento, evaluación y control, etc.).

\section{Limitantes y problemáticas del OT}

El análisis de las diferentes experiencias de ordenamiento territorial permite observar múltiples limitantes y problemáticas que afectan la puesta en marcha y la implementación de estas iniciativas. Estas problemáticas afectan a todos los niveles de organización territorial, desde el nivel nacional hasta el nivel local.

Un primer problema crítico, compartido por todos los niveles escalares y en todos los países de la región latinoamericana es la falta de coordinación interinstitucional y multiescalar en los procesos de ordenamiento territorial. Las decisiones en términos territoriales influyen en decisiones económicas y sociales, y a su vez las decisiones y acciones económicas y sociales influyen en el territorio, de allí que toda práctica de ordenamiento territorial requiere la coordinación de múltiples políticas e iniciativas sectoriales. La experiencia de los diferentes casos de análisis muestra que, a pesar de la necesidad de coordinación, existe una fuerte fragmentación y desarticulación en el proceso de planificación y gestión territorial, entre diferentes organismos y actores del mismo nivel político administrativo, como entre diferentes niveles político-administrativos (nación, provincias (estados) y municipios), (Subsecretaría de Planificación Territorial de la Inversión Pública, 2015). Esto se debe a varias razones:

a) a que las iniciativas de carácter territorial están distribuidas en múltiples y diversos organismos, tanto a nivel nacional, provincial como municipal; por tal razón, varios organismos trabajan en paralelo sobre temas similares, compartiendo el mismo territorio de acción, pero operando en forma autónoma e independiente, y no en pocas ocasiones sobreponiendo intereses sectoriales o incluso personales,

b) a que existen pocos mecanismos de articulación al interior de los ministerios, secretarías o direcciones, no existiendo además organismos (nacionales, provinciales o municipales) con capacidad de articular todas las iniciativas de carácter territorial de todos las áreas de gobierno,

c) a la superposición de roles y funciones entre los diferentes niveles escalares, pues no existe claridad sobre las incumbencias y los instrumentos de que dispone cada uno de los niveles político-administrativos para tratar las problemáticas del territorio, $y$ 
d) a que existe una fuerte competencia política entre actores, ya que los problemas del territorio son una arena de disputas, en la cual distintos actores políticos intentan posicionarse y construir su poder y sus proyectos de futuro, de manera que la problemática territorial no es atendida como un tema clave de las políticas públicas, sino que es utilizado como un mecanismo para construir poder y escalar posiciones en la esfera política (Ríos, 2011).

Por ello, una estrategia de ordenamiento territorial requiere la construcción de consensos políticos, y de liderazgos y capacidad de negociación para armonizar y mantener la coherencia entre políticas sectoriales y estrategia territorial, sin estas condiciones es muy fácil caer en una fragmentación y anarquía de iniciativas sectoriales que muchas veces impactan en forma no deseada en el territorio.

Vinculado al punto anterior, una segunda problemática clave es la debilidad de los procesos participativos. Es claro que dentro de un proceso de ordenamiento territorial se deben articular múltiples actores bajo un marco participativo y democrático, ya que este proceso involucra al conjunto de la población de un territorio. Así, no se trata solo de las actividades de los funcionarios y técnicos de un área de gobierno, sino también de los múltiples sectores del gobierno involucrados en el territorio que tienen como objeto de trabajo diferentes problemáticas del mismo (energía, educación, infraestructuras, desarrollo económico, etc.), y a la población en general, bajo una participación directa, u organizada a través de grupos, asociaciones, cámaras, etc., lo cual dependerá de la escala de trabajo y la complejidad de los procesos. Los casos de análisis muestran una gran diversidad de mecanismos y formas de participación, no obstante, estos no siempre están debidamente organizados ni suficientemente normados como para generar efectos significativos y darle al proceso una mayor sostenibilidad a través del tiempo.

Un tercer problema, ampliamente señalado en todos los casos de análisis es la carencia de un marco normativo que permita dar cumplimiento cabal a las propuestas de ordenamiento territorial. En efecto, cualquier iniciativa de ordenamiento territorial requiere para su aplicación de un dispositivo normativo que les dé sentido y valor legal (leyes, decretos, ordenanzas, etc.), sino todas las iniciativas y propuestas quedan relegadas a las buenas intenciones de los múltiples actores. Las experiencias permiten observar que la gran mayoría de las propuestas de ordenamiento no tienen un andamiaje jurídico que las sustente y estructure, y por ende que obligue a su cumplimento. El vacío normativo no permite sostener ninguna propuesta operativa de planificación y gestión territorial a largo plazo, que garantice los resultados proyectados bajo un proceso imagen-objetivo. A nivel local, los marcos normativos o leyes normalmente se centran en regular el uso del suelo urbano $u$ otras acciones vinculadas al ordenamiento territorial, sin que existan experiencias significativas de ordenanzas de carácter integral para sostener procesos de planificación y gestión 
que involucren las áreas urbanas y rurales (en este sentido, los municipios mendocinos también son la excepción, pues cuentan con ordenanzas locales para sostener los proyectos de ordenamiento territorial local, tanto urbanos como rurales).

En cuarto lugar, un tema recurrente en todos los países analizados y en todos los niveles escalares es la baja capacidad técnico-operativa en materia de planificación y gestión territorial, esto es, la falta de personal calificado, de instrumentos operativos y de ámbitos técnicos dedicados al ordenamiento. Son varios los factores que explican esta baja capacidad técnica operativa. Un primer elemento es la falta de una visión más sistémica de los procesos territoriales y un reconocimiento de la importancia de las dinámicas territoriales como estructurantes del desarrollo de los países y regiones. Esta falta de visión se traduce en la poca importancia dada a la administración territorial y por ende a las áreas de gobierno responsables de estas temáticas.

La carencia de equipos técnicos capacitados en la región es producto de la debilidad en la formación de especialistas en planificación, es recién en los últimos años que aparecen cursos de especialización y formación de grado y posgrado en temas de planificación y ordenamiento territorial más integrales. Por otro lado, en la mayoría de los países, y debido al fuerte sesgo urbano de las prácticas de ordenamiento territorial, los equipos técnicos están monopolizados por arquitectos, siendo muy limitada la participación de otros profesionales (ingenieros, geógrafos, antropólogos, economistas, sociólogos, biólogos, etc.), con la consiguiente pérdida de diversidad de miradas y de capacidades técnicas.

Otro factor clave vinculada a la baja capacidad operativa es la poco eficaz organización de áreas de planificación y ordenamiento territorial dentro de las estructuras gubernamentales. En efecto, en la mayoría de los países, las áreas de planificación territorial se encuentran subordinadas a áreas de mayor importancia en términos políticos o presupuestarios, por lo cual estas áreas restan marginales dentro de la estructura de gobierno, sin ninguna capacidad de articular políticas e iniciativas dado su bajo nivel de incidencia política.

Es necesario mencionar también la carencia de instrumentos operativos, esto es el bajo nivel de desarrollo de los instrumentos de tratamiento y visualización de la información territorial (SIG, WEB, etc.) y la casi nula utilización de modelos y métodos de planificación ya probados a nivel internacional (modelos de análisis y simulación territorial, modelos de planificación del uso del suelo, metodologías de seguimiento, evaluación y control, etc.).

La falta de información territorial de calidad, debidamente organizada y sistematizada (bases de datos, catastros) es claramente otro factor que limita los procesos de planificación y ordenamiento territorial. En muchos países, y especialmente a nivel local y regional, no se cuentan con catastros actualizados, ni con una cartografía de base que permita definir planes de ordenamiento territorial o de usos del suelo, mismo de muy baja complejidad. La falta de información no sólo limita las posibilidades de planificación, sino que además 
promueve un mayor caos en el uso del suelo dada la falta de conocimientos y de sistemas de control. En quinto lugar, un problema clave en todas las experiencias analizadas es la desconexión entre las propuestas de ordenamiento territorial y el financiamiento para obras o proyectos de envergadura con fuerte capacidad para estructurar el territorio (urbanizaciones, redes en general, planes de fomento, etc.). En efecto, generalmente las propuestas de Ordenamiento Territorial no movilizan recursos económicos per se, sino que diseña y plantea estrategias territoriales que deben ser de cumplimiento de otros sectores de gobierno que sí cuentan con recursos, y que tienen sus propias iniciativas o estrategias (planes sectoriales de desarrollo económico, de fomento industrial, de medio ambiente, de infraestructuras y equipamientos, etc.), y que muchas veces suelen ser contradictorias con la estrategia territorial. Esta desconexión entre las propuestas de ordenamiento y el financiamiento de las obras que estructuran el territorio es claramente limitante, pues para lograr la implementación de las acciones contempladas en los planes de ordenamiento se requiere un fuerte liderazgo político institucional y de primer nivel jerárquico, y se dijo anteriormente, no es el caso más usual, al contrario, las áreas de planificación están relegadas a niveles jerárquicos menores, sin capacidad de influencia en la toma de decisiones económicas y financieras.

Los retos del Ordenamiento Territorial en América Latina requieren de una recomposición multi sectorial y multi escalar, misma que permita regular, sistematizar y garantizar un proceso de planificación por etapas, pero de carácter permanente. Se requiere trabajar en un cambio de visión y paradigma en donde el territorio se asuma como el elemento central de la práctica del Ordenamiento y no el receptáculo de acciones sectoriales, por parte de los tres órdenes de gobierno, basadas en instrumentos de política pública poco eficientes para garantizar una mejora en la calidad de vida en los ámbitos urbanos, metropolitanos y rurales.

\section{Conclusiones}

\section{Propuestas de mejora de las políticas de OT en $A L$}

A manera de síntesis, producto de la investigación realizada y con la ayuda de la matriz comparativa (Figura 2), se pueden mencionar problemas comunes en torno al ordenamiento territorial que se presentan en los cuatro países analizados y que son visibles en todos los niveles escalares, a continuación, se describen los más importantes:

- Falta de coordinación interinstitucional y multiescalar en los procesos de ordenamiento territorial

- Debilidad de los procesos participativos

- Predominio de una planificación de corto y mediano plazo

- Carencia de marcos normativos 
- Baja capacidad técnico-operativa en materia de planificación y gestión territorial

- Desconexión entre las propuestas de ordenamiento territorial y el financiamiento para obras o proyectos de envergadura con fuerte capacidad para estructurar el territorio.

A partir de estos hallazgos, se proponen algunos lineamientos a considerar por cada uno de los países, lo que aportaría de manera significativa a la mejora de los procesos de ordenamiento territorial y a la aplicación de políticas públicas que viabilicen el desarrollo territorial, es por todo esto que las problemáticas observadas en torno al ordenamiento territorial obligan a repensar este tipo de iniciativas y las políticas que las sostienen, de tal manera que se pueda actuar con mayor eficacia y resolver los problemas territoriales estructurales de nuestra región. Varias son las propuestas que pueden plantearse a la luz de las diferentes experiencias analizadas.

Un primer elemento crítico para la mejora de las políticas y las iniciativas de ordenamiento territorial en América Latina es la construcción de una cultura territorial. En las últimas décadas en la región se ha logrado construir una cultura ambiental, es decir un pensamiento más permanente y genuino sobre la relación entre la sociedad y el ambiente, hecho que ha permitido escalar ideas y propuestas que han dado lugar a políticas e iniciativas más amplias por parte del gobierno, y claramente, nuevas conductas y modos de vida por parte de la población en relación con el cuidado y la protección ambiental. No sucede lo mismo con el territorio, nuestros países adolecen de un pensamiento, una cultura y una acción territorial permanente y sistemática, no sólo por parte de los diferentes niveles de gobierno, sino también por parte de la sociedad civil, el mundo empresario y las organizaciones sociales. Una cultura del territorio implica no sólo pensar en cómo se organiza la sociedad, en dónde vive, dónde trabaja, cómo se mueve, dónde la gente construye sus proyectos de vida, sino también en ser parte activa en la planificación, la gestión y la sostenibilidad de nuestros territorios y paisajes. La construcción de una mirada territorial, de una visión de futuro para y desde el territorio, que defina entre otras cosas cómo deseamos que funcione y se organice en el mediano y largo plazo constituye el eje central de una política con perspectiva de largo alcance de ordenamiento territorial. Políticas activas de comunicación, sensibilización y educación en términos territoriales, que planteen diferentes escenarios territoriales de futuro, serán claves en la construcción de esta cultura territorial.

En segundo lugar, las evidencias internacionales señalan claramente que gran parte de las políticas y prácticas de ordenamiento territorial fracasan debido a que el modelo de intervención sigue estando centrado en la acción pública, a pesar de que las dinámicas territoriales ya no responden sólo a la acción de los gobiernos (como pareció haber sido durante décadas), sino también, y en forma creciente, a la acción privada y colectiva. En efecto, son las dinámicas de los 
mercados y muchas veces también de la sociedad civil las que estructuran el funcionamiento de los territorios, especialmente a través de la movilidad de las empresas, de la puesta en valor de nuevos recursos, de las migraciones, etc. Estas acciones privadas y colectivas estructuradoras de los territorios, no siempre son consideradas en forma adecuada en las prácticas de ordenamiento territorial, razón por la cual se torna necesario construir nuevos mecanismos de planificación y gestión territorial, que articule en forma más efectiva las acciones de múltiples actores, lo cual implicará dos elementos claves: nuevos esquemas de participación y consenso estables, en donde se pueda articular al sector público, el sector privado y las organizaciones de la sociedad civil en forma más eficaz y nuevos esquemas de coordinación.

a) En lo que respecta a la participación, es imprescindible generar plataformas de diálogo y construcción de consenso entre la acción pública, colectiva y privada, es decir espacios desde donde se puedan diseñar e implementar iniciativas para los territorios, en las cuales la diversidad de los actores involucrados sean co-responsables. Dentro de estas plataformas será necesario generar mecanismos que aseguren la participación efectiva de todos los actores de manera que la planificación y la gestión territorial cuenten con la legitimidad social necesaria. Los Consejos Territoriales de Planeación u otros instrumentos pueden ser elementos o experiencias a tener en cuenta.

b) En lo que respecta a la coordinación de las iniciativas y los actores, un elemento que surge con claridad de los diagnósticos de todas las experiencias de ordenamiento territorial plantea a la falta de coordinación como un problema clave. En este sentido, una nueva lógica organizacional, transversal bajo múltiples organismos y con mayor participación, requerirá indefectiblemente desarrollar nuevos y más innovadores mecanismos de coordinación, tanto a nivel horizontal como multiescalar, para poder dar cuenta de las fuertes interconexiones entre los actores y los territorios de diferentes niveles escalares. Estos mecanismos de coordinación, imprescindibles en un nuevo contexto de redes complejas, pueden construirse dentro del contexto de plataformas de diálogo y de consenso más innovadoras. Esta construcción de nuevos mecanismos de coordinación requerirá el uso de nuevas tecnologías de la información y la comunicación, nuevas prácticas y habilidades por parte de los actores involucrados y una reingeniería institucional que otorgue más flexibilidad a los organismos para poder actuar bajo nuevas lógicas de redes.

Un tercer tema crítico es el fortalecimiento de los ámbitos político administrativos responsables del ordenamiento territorial, cualquiera que sea el nivel de gobierno (nacional, provincial, local). Las secretarías, subsecretarías, direcciones u otras áreas responsables de la puesta en marcha y la coordinación de políticas e iniciativas de ordenamiento territorial deberían ser reformuladas y 
pensadas como estructuras transversales, con vínculos con todas las áreas de gobierno, pero con una directa dependencia de los niveles de decisión más altos, manteniendo una visión global y de conjunto de las políticas con impacto territorial. Las áreas responsables de la planificación y la gestión territorial no pueden depender de estructuras sectoriales (de una secretaría de obras e infraestructuras por ejemplo), sino que requieren de cierta autonomía de gestión y fuerte capacidad de conexión institucional, viabilizada por un mayor poder político institucional, no obstante, más allá de esta reformulación de las estructuras institucionales, para que una política de ordenamiento territorial tenga eficacia es necesario que la misma tenga un carácter transversal en la gestión de gobierno y sea parte de la agenda estratégica y prioritaria de gobierno. Esta reorganización de las estructuras institucionales requiere implícitamente también un ordenamiento y el establecimiento de los roles y las funciones de los múltiples actores privados y colectivos involucrados en el territorio en vistas a construir estrategias territoriales de largo plazo.

Un cuarto elemento clave, fundamental para la construcción de procesos de ordenamiento territorial es el fortalecimiento de los instrumentos normativos. Sin leyes y reglamentaciones no hay prácticas de ordenamiento territorial válidas y eficaces. Las normativas territoriales están principalmente enfocadas en la región al uso del suelo urbano y a políticas de protección y conservación de la naturaleza, existen grandes vacíos en normativas nacionales, regionales y locales que permitan atender y regular múltiples procesos territoriales, como la construcción de infraestructuras y equipamientos, la realización de actividades productivas, etc. Pero no se trata solamente de la existencia de marcos legales, sino también de la falta de control y cumplimiento de las existentes, tema recurrente, principalmente en torno a las ciudades, tanto en sus espacios centrales como en sus áreas de nueva creación: el periurbano. Un fortalecimiento de las normativas territoriales en los países de la región debería abordar el tema de la capacitación, la creación de un Observatorio de leyes y estudios comparados, entre otras cosas (Aguilar, 2014).

Tal como se planteó anteriormente, todas las experiencias analizadas muestran claramente un déficit de capacidades técnicas e instrumentales necesarias para el ordenamiento territorial. Es imprescindible mejorar sustancialmente las capacidades técnicas en materia de ordenamiento territorial en la región. Sería sumamente importante generar una estrategia regional de capacitación y sensibilización a la planificación y la gestión territorial, no sólo de nivel universitario, sino también en la formación escolar y a través de múltiples recursos pedagógicos, con el objetivo de generar una mayor cultura de la planificación y la gestión territorial. A nivel técnico, será necesario fortalecer en la región la formación universitaria, con cursos especializados en el ordenamiento territorial, orientados a personal técnico y funcionarios de los organismos públicos. Dentro de esta estrategia, es necesario recuperar y valorizar las experiencias y lecciones aprendidas, pues gran parte de las experiencias de 
gestión territorial van quedando en el olvido. Así, se pretende que el proceso de planificación y gestión territorial constituya un espacio de aprendizaje, donde tanto los actores públicos como privados puedan aprender unos de otros y se puedan reproducir estas lecciones aprendidas para aumentar así el capital cognitivo en materia territorial en la región. La creación de redes, observatorios, centros de investigación, publicaciones científicas y otros instrumentos de formación, investigación y difusión son herramientas cada vez más habituales en la región, que deben ser potenciadas. No obstante, de nada vale generar nuevas capacidades y construir una nueva cultura de la gestión territorial si no se puede asegurar la continuidad y sostenibilidad de los equipos técnicos de planificación y gestión territorial en los diferentes niveles de gobierno de manera que no se generen recambios permanentes en el personal. En este sentido el desarrollo de la carrera profesional de especialistas en ordenamiento territorial dentro de las estructuras burocráticas administrativas de los países, y su reconocimiento político institucional, salarial y su garantía laboral puede ser un tema clave hacia futuro para sostener y acrecentar las políticas y las prácticas de ordenamiento territorial.

Finalmente, un tema no menor es la necesidad de mejorar sustancialmente los sistemas de información y de monitoreo y evaluación de las acciones. Si bien hubo en las últimas décadas un fuerte progreso en materia de información cartográfica debido al auge de los sistemas de información geográficos, no obstante, la información de carácter territorial aparece fragmentada, discontinua $y$, en muchos casos, presentando errores o lagunas. Este es un problema que afecta muy especialmente a países de gran tamaño (Brasil, Argentina, México) y a países con fuerte debilidad institucional en sus áreas de cartografía (Paraguay).

Avanzar en políticas y prácticas de ordenamiento territorial en América Latina implicará avanzar en la resolución de las problemáticas planteadas y en esta serie de recomendaciones, muy sintéticas, pero claves para mejorar la eficacia de estas prácticas.

\section{Bibliografía}

Aguilar, G., "Del proyecto de ciudad a la ciudad sin proyecto: El desarrollo histórico territorial de la traza urbana de la ciudad de Valladolid-Morelia 1541-2009", en Vieyra, A y Larrazábal, A. (coords.), Urbanización, sociedad y ambiente: Experiencias en ciudades medias, 2014.

Amilhat Szary, A., "L'intégration continentale aux marges du Mercosur: les échelles d'un processus transfrontalier et transandin", in Revue de Geographie Alpine, tome 1, no. 3, 2003.

Banco Mundial, Agriculture for development. World development report 2008, World Bank, Washington, 2007, 365 pp.

Bebbingon, A. \& Bury, J. (eds.), Subterranean Struggles: New Dynamics of Mining, Oil, and Gas in Latin America. Austin, USA, University of Texas Press, 2013. 
Bosque, Joaquín y Francisco Ortega, Comentario de textos geográficos historia y crítica del pensamiento geográfico, Barcelona, Oikos Tau, 1995.

Castro, L., Urbanización periférica y agricultura periurbana: localización espacial y caracterización de los sistemas agropecuarios del municipio de Tarímbaro, Michoacán, Universidad Nacional Autónoma de México, México, 2014.

CEPAL - Naciones Unidas, "El Ministerio de Planificación y la CEPAL analizan la dinámica económica argentina y su configuración territorial. Comisión Económica para América Latina y el Caribe”, 2014. Recuperado de https://www.cepal.org/es/notasinformativas/el-ministerio-de-planificacion-y-la-cepal-analizan-la-dinamicaeconomica

Esparza Valdivia, H. \& Martín, H., "La planeación en los Estados”, Revista Alegatos, núm. 31, septiembre-diciembre, 1995, pp. 487-492.

Estados Unidos Mexicanos, Ley sobre Planeación General de la República, Diario Oficial de la Federación, 12 de julio de 1930, D.F. México, 1930.

FAO, "Agricultura familiar en América latina y el Caribe: recomendaciones de política", S. Salcedo \& L. Gusmán (eds.). Santiago de Chile, 2014.

Gaignard, R., "Le Paraguay”, in Delavaud, C., L'Amérique latine, approche géographique régional, Paris, Bordas, tome 2, 1973, pp. 115-135.

Guibert, M., Sili, M., Arbeletche, P., Piñeiro, D., \& Grosso, S., "Les nouvelles formes d'agriculture entrepreneuriale en Argentine et en Uruguay", Économies et Sociétés, vol. 10, no. 33, 2011, pp. 1808-1825.

Hall, Peter, Las ciudades del mañana. Historia del urbanismo en el siglo xx, Barcelona, Ediciones del Serbal, 1996.

Kleinpening, J., Man and Land in Paraguay, CEDL, Amsterdam, 1987.

López, M. Fernanda, El sistema de planifación y el ordenamiento territorial para el "Buen Vivir" en el Ecuador, vol. 19, núm. 2, pp. 297-312.

Méndez, Y. y Vieyra A., "Tracing Processes in Poverty Dynamics: A Tale of Peri-urban Smallscale Farmers in Mexico City" Urban Studies, vol. 51, no. 10, UK, 2014, pp. 2009-2035. DOI: $10.1177 / 0042098013505923$.

Moreno Valle, J., "Apuntes para una historia de la Planeación en México", Revista de Administración Pública, núm. 39, 1979, pp. 45-60.

Naciones Unidas. Objetivos de Desarrollo Sostenible, 2018. Recuperado de https://www.un.org/sustainabledevelopment/es/objetivos-de-desarrollosostenible/

Quenan, C. \& Velut, S., Les enjeux du développement en Amérique Latine, Institut des Amériques, Ed. Agence Française de Développement, Paris, 2014.

Safarov, A., "El territorio como factor dinámico de la integración: la ZICOSUR", Revista Persona, Buenos Aires, 2000.

Secretaría Técnica de Planificación del Desarrollo Económico y Social (STP), Guía para la elaboración de los Planes de Ordenamiento Urbano y Territorial, Asunción, Paraguay, 2016. Recuperado de http://www.stp.gov.py/v1/wp-content/uploads 2018/07/Guia-POUT.pdf

SENPLADES, Plan Nacional de Desarrollo, 2017-2021, Toda una Vida (C Secretaría Nacional de Planificación y Desarrollo, 2017, Quito, Ecuador. 
Sili, M., "La transformación de la distribución, el uso y la tenencia de la tierra en el Noreste argentino. Una visión de síntesis", Revista Interuniversitaria de Estudios Territoriales, Pampa, núm. 7, 2011, pp. 187-206.

Sili, M. y Rodríguez, J., Acción Territorial: la experiencia reciente de los municipios del Paraguay, Secretaría Técnica de Planificación del Desarrollo Económico y Social, Asunción, Paraguay, 2017.

Unikel, L., Ruiz Chiapetto, C. \& Garza, G., El desarrollo urbano de México: diagnóstico e implicaciones futura, 1978. 
Anexo 1

Guía de entrevistas para el análisis de prácticas y políticas de OT

\section{Objetivos}

¿Podría comentar cómo y porqué surge este plan y cuál es su objetivo?

\section{Trayectoria del plan y vinculación con otras iniciativas}

¿Cómo ha sido la evolución histórica de este Plan y el estado de situación en la actualidad?

¿Este plan o iniciativa se vincula con otras iniciativas de desarrollo?

\section{Componentes y actividades del plan}

¿Cuáles son los componentes que tiene este plan de OT?

Actores involucrados y liderazgos (públicos, privados, colectivos)

¿Quiénes son los actores que lo pusieron en marcha y quienes permanecen involucrados en el mismo, tanto del sector público, del sector colectivo y del sector privado?

\section{Modelo de gobernanza}

¿Cómo se han organizado para diseñar e implementar este plan de OT?

\section{Estructura organizacional}

Mecanismos de participación

Conflictos o cooperación

\section{Presupuesto}

¿Este proyecto ha tenido un presupuesto específico? ¿Cómo evoluciono su financiamiento?

\section{Recursos técnicos}

¿Con qué recursos técnicos contó dicho plan de OT? ¿Había un equipo técnico capacitado y disponible para llevarlo adelante? ¿De dónde provienen o dónde trabajan estos técnicos? (para identificar recursos humanos). 


\section{Normativas (de sostén y de aplicación)}

¿Había una ley, decreto o resolución que apoyara el proceso de creación y puesta en marcha del plan, o sólo se hizo por la buena voluntad de los actores e Instituciones? (para identificar el nivel de reconocimiento legal de esta iniciativa) ¿Este plan de OT dio lugar a normativas, leyes o decretos? (para identificar los productos normativos generados)

¿Existen contradicciones entre el instrumento normativo y el Plan?

\section{Nivel de implementación del plan}

¿Cuál ha sido el nivel de implementación del Plan? ¿Por qué?

¿Las iniciativas implementadas han generado un impacto positivo en el territorio, tal como se esperaba?

\section{Factores claves de implementación (que inhiben o viabilizan la iniciativa)}

¿Cuáles han sido los principales factores que limitaron su implementación? ¿Podría jerarquizarlos y explicarlos?

¿Cuáles fueron los factores que facilitaron la implementación de este proyecto? ¿Podría jerarquizarlos y explicarlos?

¿Cuál sería su recomendación para mejorar la ejecución concreta de esta iniciativa? 